\title{
PRODUTIVIDADE DA VIDEIRA 'NIAGARA ROSADA' EM CULTIVO INTERCALAR COM ADUBOS VERDES ${ }^{1}$
}

\author{
ELAINE BAHIA WUTKE², MAURILO MONTEIRO TERRA², ERASMO JOSÉ PAIOLI PIRES², \\ IVAN JOSÉ ANTUNES RIBEIRO², AFONSO PECHE FILHO ${ }^{2}$
}

RESUMO - Devido ao aumento no custo de produção com a utilização de cobertura morta com capim nas ruas da videira 'Niagara Rosada' e à dificuldade para sua aquisição, objetivou-se a possibilidade de substituíla por plantas de cobertura de solo nas entrelinhas da videira. Em experimentos realizados em cinco safras, em Indaiatuba, numa entrelinha, e em três em Jundiaí, em duas entrelinhas-SP, no período de 1999/2000 a 2003/2004, conduziram-se seis tratamentos nas entrelinhas, em blocos ao acaso e com quatro repetições, constando de área no limpo; vegetação espontânea roçada; cobertura com capim seco de Brachiaria decumbens (testemunha); coberturas de aveia-preta (Avena strigosa), chícharo (Lathyrus sativus) ou de tremoço-branco (Lupinus albus), de março a outubro, seguidas de mucuna-anã (Mucuna deeringiana) de outubro a março. Determinaram-se número de cachos planta ${ }^{-1}$, produtividade de frutos $\left(\mathrm{kg} \mathrm{planta}^{-1}\right)$ e massa do cacho de uva (g), comparando-se os valores médios pelo teste de Duncan, ao nível de 5\%. Nas análises conjuntas por local, constataram-se mais diferenças significativas entre safras do que propriamente entre os tratamentos ou na interação safra x tratamentos, sobretudo em Indaiatuba. Os valores foram significativamente sempre superiores em 2001/2002 para produtividade e massa de cacho nos dois locais e, para número de cachos, em 1999/2000, em Indaiatuba, e em 2000/2001, em Jundiaí. Houve efeito dos tratamentos de cobertura nas três safras apenas em Jundiaí, com resultados similares ou até superiores das coberturas vegetais em relação à cobertura com capim seco, com destaque, particularmente, da cobertura com tremoço seguida de mucuna-anã. Independentemente do número de entrelinhas cultivadas, pode-se substituir a cobertura tradicional de capim por coberturas vegetais intercalares com gramínea e leguminosas, o ano todo, sem interferência negativa na produtividade quantitativa da videira.

Termos para indexação: Vitis spp., tratos culturais, manejo e conservação do solo; sistemas de produção.

\section{PRODUCTIVITY OF 'NIAGARA ROSADA' GRAPES ON INTERCROP PLANTING OF GREEN MANURING}

\begin{abstract}
Influence of green covers on yield of the table grape variety Niagara Rosada. In order to evaluate the possibility of replacing the traditionally used mulch by cover cropping (green manuring species) in the inter-row strip, maintaining its productivity, two experiments were carried out in Indaiatuba and Jundiaí, SP, Brazil, from 1999/00 to 2003/04, with the table grape variety Niagara Rosada. The experimental design was a randomized block with four replications and six treatments: no weeded; spontaneous local vegetation cutting; usual mulch of Brachiaria decumbens (check) and three other treatments with cover crops Avena strigosa, Lathyrus sativus and Lupinus albus, from March to October, followed by Mucuna deeringiana from October to March. Productivity, the number and the weight of cluster of grape were evaluated. The medium values were compared by using the Duncan test at $5 \%$ of significance. According to the average of the years, the results of all characteristics observed in the treatments with the green cover were similar ou more favorable than those ones using mulch cover. This leads to the conclusion that it is possible to cultivate green manure crops in the inter-rows of a grape vineyard instead of the mulch, without any negative interference on productivity of the grapevine.
\end{abstract}

Index terms: Vitis spp., cultural practices, soil management and conservation, production systems.

\footnotetext{
${ }^{1}$ Trabalho Sinfruit 111 - Simpósio Internacional de Fruticultura - Avanços na Fruticultura (17 a 21 Outubro) Apoio financeiro: Tesouro do Estado, Infraestrutura FAPESP, PRONAF.

${ }^{2}$ Engenheiro(a) Agrônomo(a), Pesquisador(a) Científico(a), Instituto Agronômico-IAC, Caixa Postal 28, 13001-970, Campinas, SP. E-mails: ebwutke@iac.sp.gov.br; mmterra@iac.sp.gov.br; ejppires@iac.sp.gov.br; peche@iac.sp.gov.br
} 


\section{INTRODUÇÃO}

O cultivo de uvas comuns para mesa está bastante difundido por todo o Estado de São Paulo, sendo $85 \%$ das áreas com 'Niagara Rosada' e produção de 105 mil t, concentrada nas regiões tradicionais de Jundiaí, Indaiatuba, Itupeva, Louveira, Campinas, Valinhos, Vinhedo, Atibaia, Jarinu, Joanópolis, Morungaba, Monte Alegre do Sul, Porto Feliz e Itatiba, predominantemente em propriedades familiares, com áreas médias de 5 ha, em sistema de meação (Miqueletto et al., 2000; SAto, 2000; Verdi, 2010). Um dos tratos culturais usualmente adotados nas ruas do vinhedo é a utilização de cobertura "morta" ou seca, composta por restos vegetais secos de capim-braquiária (Brachiaria decumbens Stapf), capim-gordura (Melinis minutifloria P. Beauv.) ou capim-napier ou elefante (Pennisetum purpureum), bagaço de cana-de-açúcar, serragem e casca de eucalipto, dentre outros. É distribuída no outono-inverno, sobretudo para prevenção e controle da erosão e da população de infestantes, para manutenção de umidade e temperatura adequadas no perfil do solo e aumento do teor de matéria orgânica no solo, facilitando os demais tratos culturais nesse período, mas com resultados distintos na propriedade. Esse capim, entretanto, é produzido e cortado em outro local e transportado até o parreiral, com dificuldade e custos extras para aquisição, transporte e distribuição nas ruas da videira (Melo; Maia, 2001; Pires; Martins, 2003; Pommer et al., 1998; Sousa et al., 1996; Terra et al., 1998; WutKe et al., 2010). Em algumas ocasiões, tem-se até escassez para essa cobertura morta (BRAGA, 1986), sendo os viticultores motivados a utilizarem alternativas igualmente vantajosas, como as coberturas vegetais específicas e adaptadas, sem prejuízos à videira, como exemplificado em extensa literatura relacionada em WUTKE et al. (2009; 2010). Além disso, mais recentemente, constata-se adesão crescente ao cultivo das variedades comuns de 'Niagara' em substituição às uvas europeias para mesa em áreas do noroeste e sudoeste do Estado de São Paulo (Kitahara, 2010; Siqueira, 2008). A adubação verde intercalar com espécies adaptadas às condições edafoclimáticas regionais pode ser uma relevante alternativa, a ser avaliada a médio e longo prazos, com base na periodicidade, na racionalização de sua aplicação e na flexibilidade de alteração na escolha das culturas, em decorrência de oscilações climáticas e de mercado (WutKe, 1993; 2001). Destacam-se, para esse propósito, as fabáceas tremoço-branco (Lupinus albus L.), e chícharo (Lathyrus sativus L.), e as poáceas aveia-preta (Avena strigosa) e centeio (Secale cereale), no inverno, período de repouso da videira, sem cuidados adicionais em seu cultivo, além de mucuna-anã (Mucuna deeringiana) e crotalária-júncea (Crotalaria juncea) como opções de primavera-verão (BRAGA, 1986; BULISANI; ROSTON, 1983; Pommer et al., 1998; SousA et al., 1996; WutKe, 2001; WuTKE et al., 2004; 2005). Embora a adubação verde nos vinhedos seja uma das mais antigas práticas culturais nessa cultura (VILla MaIOR, 1881; citado em SousA et al., 1996), as informações a respeito ainda são escassas, seus efeitos são contraditórios, como relatado por SousA et al. (1996) e compilado em WUTKE et al. (2010). Objetivou-se, neste trabalho, determinar a possibilidade de substituição da cobertura morta tradicional com capim-braquiária por espécies de adubos verdes, durante todo o ano e por alguns anos, sem prejuízos à produtividade quantitativa da videira 'Niagara Rosada'.

\section{MATERIAL E MÉTODOS}

Os experimentos foram desenvolvidos de 1999/2000 a 2003/2004, em propriedade de agricultura familiar no Sítio dos Meninos, em Indaiatuba e, de 1999/2000 a 2001/2002, na Estação Experimental de Agronomia de Jundiaí, do Instituto Agronômico-IAC, ambas representativas das condições de exploração agrícola da videira 'Niagara Rosada' na região, cujo clima é do tipo Cwa. Os solos são do tipo Cambissolo latossólico, cuja fertilidade foi média a elevada durante todos os anos da experimentação, sendo inicialmente determinados teores respectivos, em Indaiatuba e Jundiaí, de: 28 e $18 \mathrm{~g}$ $\mathrm{dm}^{-3}$ de matéria orgânica; 5,0 e 5,2 de pH; 46 e $67 \%$ de V\%; 102 e $155 \mathrm{mg} \mathrm{dm}^{-3}$ de P (resina); e, em mmol $\mathrm{dm}^{-3}, 2,9$ e 9,3 de K; 38 e 35 de Ca e 4 e 15 de $\mathrm{Mg}$. Nesses locais, os parreirais estavam sendo sustentados em espaldeira com quatro fios de arame, sobre porta-enxerto IAC-766 'Campinas' e com cobertura morta de Brachiaria decumbens nas ruas da videira. Utilizaram-se, respectivamente, parreirais de ano e meio, no espaçamento de $1,7 \mathrm{~m} \mathrm{x} \mathrm{1,0} \mathrm{m,} \mathrm{e} \mathrm{de} \mathrm{oito}$ anos, no espaçamento de $2 \mathrm{~m} \times 1 \mathrm{~m}$, no Sítio dos Meninos, em Indaiatuba e em Jundiaí-SP. Nas ruas da videira, foram instalados seis tratamentos, em delineamento de blocos ao acaso, com quatro repetições, e mesma distribuição nos blocos em todos os anos. Os tratamentos foram: rua no limpo o ano todo; vegetação espontânea manejada; testemunha com cobertura seca de capim-braquiária (Brachiaria decumbens) e coberturas de aveia-preta (Avena strigosa), chícharo (Lathyrus sativus) ou de tremoço-branco (Lupinus albus) no outono-inverno, de março/abril a outubro, até a colheita de sementes, seguidas de cobertura de mucuna-anã (Mucuna deeringiana), na primavera- 
-verão, de outubro a março, para fitomassa. A vegetação espontânea predominante foi picão-preto (Bidens pilosa), nabiça (Raphanus raphanistrum) e amendoim-bravo (Euphorbia heteroplylla), em Indaiatuba, e tiririca (Cyperus rotundus), picão-branco (Galinsoga parviflora), beldroega (Portulaca oleracea) e caruru (Amaranthus deflexus), em Jundiaí. A parcela tinha duas e três linhas da videira com $8 \mathrm{~m}$ de comprimento e áreas de 16 e $32 \mathrm{~m}^{2}$ em Indaiatuba e Jundiaí, respectivamente, com seis plantas da videira na área útil de cada parcela, desprezando-se as plantas das extremidades. Os adubos verdes foram semeados manualmente, sem adubação, em apenas uma rua da videira, no primeiro local, e em duas ruas por canteiro, no segundo. As sementes das leguminosas foram distribuídas em quatro linhas espaçadas $0,5 \mathrm{~m}$ entre si, e as da gramínea, em sete linhas espaçadas 0,25 $\mathrm{m}$ entre si, distanciadas $0,25 \mathrm{~m}$ das linhas da videira. Foram adotados os tratos culturais recomendados para a cultura (Pommer et al., 1998). Na área útil do canteiro, colheram-se os frutos de seis plantas, para a determinação da produtividade da videira, em $\mathrm{kg}$ planta $^{-1}$, do número médio de cachos por planta e da massa do cacho, além de amostragem da fitomassa verde de cada adubo verde, em $1 \mathrm{~m}^{2}$, seguida de secagem por $48 \mathrm{~h}$ a $80^{\circ} \mathrm{C}$. Os dados médios foram comparados por local, pelo teste de Duncan, a 5\% de probabilidade.

\section{RESULTADOS E DISCUSSÃO}

Realizaram-se duas a três colheitas parciais por safra e local, de dezembro a janeiro. Os dados de número de cachos por planta, de massa de cachos e de rendimentos médios de frutos por planta estão na Tabela 1, e os de fitomassa seca acumulados em cada sucessão de adubos verdes, na Tabela 2. Em relação ao número de cachos por planta, não se detectaram diferenças significativas entre tratamentos, em Indaiatuba, nas cinco safras. Em Jundiaí, isso foi constatado apenas na terceira e última safra, e, na média nesse local, o valor do tratamento com chícharo foi significativamente inferior apenas aos com tremoço e vegetação espontânea. Na análise conjunta, determinou-se significância entre anos, nos dois locais, com valores significativamente superiores no primeiro ano em Indaiatuba e no terceiro em Jundiaí. Os valores médios relatados nas distintas safras, de 13 e 12 cachos, eem ambos os locais, entretanto, são assemelhados entre si e bastante similares aos 13,8 cachos, média de seis safras de 'Niagara Rosada' sobre IAC-766, em Monte Alegre do Sul-SP (Terra et al., 2003) e aos 12,7 cachos por planta de 'Niagara Rosada', em duas épocas de poda, em Jataí-GO (Assis et al., 2008). De acordo com critérios de Instrução Normativa (BENATO, 2002; BrASIL, 2002) e com as médias dos tratamentos nos dois locais, os cachos podem ser considerados de massa pequena, entre $151 \mathrm{~g}$ e $250 \mathrm{~g}$, sendo médios, entre $251 \mathrm{~g}$ e $800 \mathrm{~g}$, apenas na terceira safra, em Indaiatuba. Não houve diferenças entre tratamentos para a massa de cacho a cada ano em Indaiatuba, mas apenas em Jundiaí, com destaque para o tratamento tremoço/mucuna no segundo ano, e tremoço/mucuna e testemunha da cobertura com capim e de aveia-preta/mucuna no terceiro ano. Na análise conjunta, verificou-se significância entre anos, nos dois locais, com destaques significativos para os terceiros anos em cada local. Na média dos anos, o tratamento com tremoço/mucuna foi semelhante à área capinada $\mathrm{e}$ superior aos demais. Os valores médios em Indaiatuba, de 196 a 203 g, são próximos aos 209g obtidos por Botelho (2002) e aos 191,9 a 206,3 g obtidos em duas épocas de poda, em Jataí-GO (Assis et al., 2008), ambos em 'Niagara Rosada'. Nos dois locais, os valores médios são bastante superiores aos $143 \mathrm{~g}$, determinados em Caldas-MG (Alvarenga, 2002), aos $171 \mathrm{~g}$, média de nove anos de cultivo de 'Niagara Rosada', em Jundiaí-SP (Terra et al, 1987; 1988), porém, utilizando-se apenas de cobertura de capim nas ruas da videira, e similares à média de 199 g por cacho de Niagara Rosada, em duas épocas de poda em Jataí-GO (Assis et al., 2008). São, entretanto, inferiores aos 229,5 g, determinados em seis safras em Monte Alegre do Sul (Terra et al., 2003), localidade com temperaturas bem mais amenas durante o ciclo da planta. O número e massa dos cachos são alguns dos principais componentes da produtividade e podem ser influenciados pelo clima a cada ano (Leão; Souza, 2003). Com o aumento do número de cachos, obteve-se aumento na produtividade, sobretudo em Jundiaí, como salientado por Leão e Maia (1998). Isso também pode ser aventado como um dos reflexos dos efeitos positivos da adubação verde, relatados na literatura disponível (BuLISANI; Miyasaka, 1992; Bulisani; Roston, 1983; Calegari, 1992; Sousa et al., 1996; WutKe, 1993; 2010). Na maioria dos dados de produtividade de frutos, não houve diferenças significativas entre tratamentos, nos dois locais e safras, mas sim na análise conjunta, entre anos nos dois locais, com destaque significativo para a terceira safra $(2001 / 2002)$. Nas médias dos tratamentos por local, apenas em Jundiaí constatou-se diferença estatística, sendo o menor valor com chícharo, mas apenas em relação ao tremoço e à área no limpo. Os valores médios por planta nos distintos anos e nos dois locais $(2,51$ e 2,30 kg) são inferiores às médias de 3,0 e 3,2 $\mathrm{kg}$ por planta, determinadas, 
respectivamente, em Indaiatuba (GHILARDI; MAIA, 2001) e na média de seis safras em Monte Alegre do Sul (Terra et al., 2003). São, entretanto, similares aos $2,55 \mathrm{~kg}$, referentes à média de nove anos de cultivo de 'Niagara Rosada' em Jundiaí (TERRA et al., 1998). Em geral, em todos os parâmetros avaliados, os valores determinados em Indaiatuba foram sempre superiores aos de Jundiaí, talvez devido à menor idade do vinhedo no primeiro local e às diferenças nos tratos culturais. Houve nítida influência das distintas condições climáticas nos resultados e não das diferentes coberturas verdes utilizadas, da vegetação espontânea roçada ou das ruas mantidas no limpo, além da própria cobertura de capim seco, já que, para a maioria das diferenças nos três parâmetros, houve mais influência das safras. Essa mesma tendência foi constatada para a fitomassa dos adubos verdes em Indaiatuba, mas não em Jundiaí, onde houve efeito da interação safra $\mathrm{x}$ fitomassa total dos adubos verdes (Tabela 2). Para este parâmetro, verificou-se superioridade média para as sucessões com tremoço e aveia-preta, respectivamente, em Indaiatuba e Jundiaí. Em geral, para todos os anos, locais e sucessões, os valores acumulados de quantidade de fitomassa estavam na faixa de variação dessas espécies, como compilado de diversos autores e apresentado por Wutke et al. (2009). Os resultados superiores em parâmetros da videira, na terceira safra (2001/2002), em ambos os locais, foram possivelmente determinados pela maior precipitação pluvial registrada durante a frutificação das plantas e pela temperatura. Da poda à colheita dos frutos, entre agosto e dezembro, as temperaturas médias, particularmente nessa safra, estavam na faixa entre $25^{\circ}$ e $30^{\circ} \mathrm{C}$, considerada ótima para o cultivo da uva (MAiA; CAMArgo, 2001). Ainda, as diferenças constatadas entre os tratamentos para todos os parâmetros, em Jundiaí, podem estar também relacionadas ao menor teor de matéria orgânica constatado inicialmente nessa localidade, $18 \mathrm{~g} \mathrm{dm}^{-3}$, bastante inferior aos $28 \mathrm{~g} \mathrm{dm}^{-3}$, em Indaiatuba, onde não se constatou tal discriminação. Como constatado nos dados da Tabela 2, particularmente em Jundiaí, com a utilização continuada de cobertura verde intercalar ao longo do tempo, pode-se esperar reposição ou manutenção da matéria orgânica, com consequente contribuição à manutenção de efeitos favoráveis na videira, como enfatizado na literatura (MANERA, 1986; Sousa, 1996; Sousa et al., 1996; WutKe, 2001; WuTKE et al., 2010). Comparativamente à utilização da cobertura seca de capim, Wutke et al. $(2004 ; 2005)$ também não constataram interferência negativa da adubação verde intercalar na qualidade dos frutos de 'Niagara Rosada'. 
TABELA 1 - Número e massa de cachos e produtividade de frutos por planta de uva 'Niagara Rosada'. Indaiatuba e Jundiaí-SP. 1999/2000 a 2003/2004.

\begin{tabular}{|c|c|c|c|c|c|c|c|c|c|c|}
\hline \multirow{2}{*}{$\begin{array}{l}\text { Trata } \\
\text { mento }\end{array}$} & \multicolumn{5}{|c|}{ Indaiatuba } & \multirow[t]{2}{*}{ Média } & \multicolumn{3}{|c|}{ Jundiaí } & \multirow[t]{2}{*}{ Média } \\
\hline & $99 / 00$ & $00 / 01$ & $01 / 02$ & $02 / 03$ & 03/04 & & $99 / 00$ & $00 / 01$ & $01 / 02$ & \\
\hline & \multicolumn{10}{|c|}{ Número de cachos por planta } \\
\hline $1^{1 /}$ & 16 & 6 & 15 & 14 & 12 & $13 \mathrm{a}$ & 10 & 10 & $17 \mathrm{ab}$ & $12 \mathrm{ab}$ \\
\hline 2 & 17 & 6 & 14 & 13 & 12 & $13 \mathrm{a}$ & 9 & 10 & $19 \mathrm{ab}$ & $13 \mathrm{a}$ \\
\hline 3 & 17 & 7 & 14 & 13 & 12 & $13 \mathrm{a}$ & 9 & 11 & $16 \mathrm{ab}$ & $12 \mathrm{ab}$ \\
\hline 4 & 17 & 7 & 15 & 12 & 11 & $12 \mathrm{a}$ & 10 & 10 & $20 \mathrm{a}$ & $13 \mathrm{a}$ \\
\hline 5 & 17 & 6 & 15 & 12 & 12 & $13 \mathrm{a}$ & 8 & 9 & $16 \mathrm{ab}$ & $11 \mathrm{~b}$ \\
\hline 6 & 17 & 8 & 15 & 13 & 11 & $13 \mathrm{a}$ & 11 & 9 & $19 \mathrm{ab}$ & $13 \mathrm{a}$ \\
\hline Média & $17 \mathrm{~A}$ & $7 \mathrm{E}$ & $15 \mathrm{~B}$ & $13 \mathrm{C}$ & $12 \mathrm{D}$ & 13 & $10 \mathrm{~B}$ & $10 \mathrm{~B}$ & $18 \mathrm{~A}$ & 12 \\
\hline $\mathrm{CV} \%$ & 9,4 & 13,1 & 7,2 & 13,2 & 11,6 & 10,7 & 17,4 & 13,6 & 12,7 & 14,4 \\
\hline
\end{tabular}

$\begin{array}{lcccccccccc}1^{1 /} & 169,0^{2 /} & 206,9 & 275,8 & 202,4 & 123,3 & 196 \mathrm{a} & 135,8 & 200,3 \mathrm{~b} & 234,6 \mathrm{a} & 190 \mathrm{ab} \\ 2 & 160,7 & 223,4 & 298,2 & 215,3 & 116,5 & 203 \mathrm{a} & 114,2 & 179,2 \mathrm{~b} & 207,0 \mathrm{ab} & 167 \mathrm{c} \\ 3 & 175,0 & 221,9 & 268,0 & 206,9 & 138,5 & 202 \mathrm{a} & 131,4 & 180,5 \mathrm{~b} & 196,8 \mathrm{~b} & 169 \mathrm{c} \\ 4 & 160,9 & 198,0 & 283,2 & 194,9 & 159,2 & 199 \mathrm{a} & 119,9 & 194,9 \mathrm{~b} & 199,9 \mathrm{~b} & 172 \mathrm{c} \\ 5 & 165,4 & 216,6 & 283,5 & 196,5 & 135,0 & 199 \mathrm{a} & 115,0 & 202,7 \mathrm{~b} & 217,2 \mathrm{ab} & 178 \mathrm{bc} \\ 6 & 153,6 & 220,5 & 293,3 & 201,6 & 126,3 & 199 \mathrm{a} & 128,8 & 227,2 \mathrm{a} & 229,5 \mathrm{a} & 195 \mathrm{a} \\ \text { Média } & 164,1 \mathrm{D} & 214,5 \mathrm{~B} & 283,7 \mathrm{~A} & 202,9 \mathrm{C} & 133,1 \mathrm{E} & 200 & 124,2 \mathrm{C} & 197,5 \mathrm{~B} & 214,2 \mathrm{~A} & 179 \\ \text { CV\% } & 11,7 & 11,8 & 4,6 & 7,0 & 17,8 & 9,9 & 18,3 & 8,0 & 8,4 & 10,7\end{array}$

\begin{tabular}{lcccccccccc}
$1^{1 /}$ & 2,77 & $1,28 \mathrm{c}$ & $4,22 \mathrm{ab}$ & 2,75 & 1,45 & $2,50 \mathrm{a}$ & 1,34 & 1,94 & $3,99 \mathrm{ab}$ & $2,42 \mathrm{ab}$ \\
2 & 2,76 & $1,41 \mathrm{abc}$ & $4,17 \mathrm{ab}$ & 2,82 & 1,41 & $2,57 \mathrm{a}$ & 1,07 & 1,76 & $3,84 \mathrm{abc}$ & $2,23 \mathrm{bc}$ \\
3 & 2,91 & $1,60 \mathrm{ab}$ & $3,83 \mathrm{~b}$ & 2,65 & 1,64 & $2,56 \mathrm{a}$ & 1,17 & 1,96 & $3,21 \mathrm{c}$ & $2,11 \mathrm{bc}$ \\
4 & 2,71 & $1,35 \mathrm{bc}$ & $4,13 \mathrm{ab}$ & 2,35 & 1,72 & $2,42 \mathrm{a}$ & 1,15 & 2,02 & $3,89 \mathrm{ab}$ & $2,35 \mathrm{abc}$ \\
5 & 2,82 & $1,37 \mathrm{bc}$ & $4,29 \mathrm{ab}$ & 2,41 & 1,64 & $2,47 \mathrm{a}$ & 0,98 & 1,81 & $3,41 \mathrm{bc}$ & $2,07 \mathrm{c}$ \\
6 & 2,69 & $1,64 \mathrm{a}$ & $4,49 \mathrm{a}$ & 2,56 & 1,41 & $2,56 \mathrm{a}$ & 1,47 & 2,14 & $4,26 \mathrm{a}$ & $2,62 \mathrm{a}$ \\
Média & $2,78 \mathrm{~B}$ & $1,44 \mathrm{C}$ & $4,19 \mathrm{~A}$ & $2,59 \mathrm{~B}$ & $1,55 \mathrm{C}$ & 2,51 & $1,20 \mathrm{C}$ & $1,94 \mathrm{~B}$ & $3,77 \mathrm{~A}$ & 2,30 \\
CV\% & 11,1 & 10,9 & 8,3 & 16,0 & 21,0 & 12,9 & 33,2 & 17,4 & 11,0 & 16,7 \\
\hline
\end{tabular}

"11: sempre no limpo; 2: vegetação espontânea roçada; 3: cobertura de capim seco; 4: cobertura de aveia-preta (Avena strigosa) no outono-inverno e de mucuna-anã (Mucuna deeringiana) na primavera-verão; 5: cobertura de chícharo (Lathyrus sativus) no outono-inverno e de mucuna-anã na primavera-verão; 6: cobertura de tremoço-branco (Lupinus albus) no outono-inverno e de mucuna-anã na primavera-verão; ${ }^{2 /}$ Média de seis plantas por parcela.

Médias seguidas pelas mesmas letras minúsculas nas colunas, para cada local, e maiúsculas nas linhas não são diferentes entre si, pelo teste de Duncan, a 5\% de probabilidade.

TABELA 2 - Quantidade de fitomassa seca acumulada em cada sucessão de adubos verdes por safra de uva 'Niagara Rosada'. Indaiatuba e Jundiaí-SP. 1999/2000 a 2003/2004.

\begin{tabular}{|c|c|c|c|c|c|c|c|c|c|c|}
\hline \multirow{2}{*}{$\begin{array}{l}\text { Trata } \\
\text { mento }\end{array}$} & \multicolumn{5}{|c|}{ Indaiatuba } & \multirow[t]{2}{*}{ Média } & \multicolumn{3}{|c|}{ Jundiaí } & \multirow[t]{2}{*}{ Média } \\
\hline & $99 / 00$ & $00 / 01$ & $01 / 02$ & $02 / 03$ & $03 / 04$ & & 99/00 & $00 / 01$ & $01 / 02$ & \\
\hline & \multicolumn{10}{|c|}{$\mathrm{Kg} \mathrm{m}^{-2}$} \\
\hline $\mathrm{A}+\mathrm{M}^{1 /}$ & $0,806 a$ & $0,266 \mathrm{c}$ & $0,756 \mathrm{c}$ & $0,295 b$ & $0,287 \mathrm{~b}$ & $0,482 b$ & $0,554 \mathrm{a}$ & $0,548 \mathrm{a}$ & $0,598 \mathrm{~b}$ & $0,567 \mathrm{a}$ \\
\hline $\mathrm{C}+\mathrm{M}$ & $0,619 b$ & $0,270 \mathrm{~b}$ & $0,836 \mathrm{~b}$ & $0,350 \mathrm{a}$ & $0,296 \mathrm{a}$ & $0,474 \mathrm{c}$ & $0,555 b$ & $0,527 \mathrm{~b}$ & $0,558 \mathrm{c}$ & $0,548 b$ \\
\hline $\mathrm{T}+\mathrm{M}$ & $0,686 \mathrm{c}$ & $0,292 \mathrm{a}$ & $0,950 \mathrm{a}$ & $0,291 \mathrm{a}$ & $0,259 \mathrm{c}$ & $0,496 \mathrm{a}$ & $0,480 \mathrm{c}$ & $0,487 \mathrm{c}$ & $0,680 \mathrm{a}$ & $0,548 \mathrm{~b}$ \\
\hline Média & $0,704 \mathrm{~B}$ & $0,276 \mathrm{E}$ & $0,847 \mathrm{~A}$ & $0,312 \mathrm{C}$ & $0,281 \mathrm{D}$ & 0,484 & $0,529 \mathrm{~B}$ & $0,520 \mathrm{C}$ & $0,612 \mathrm{~A}$ & 0,554 \\
\hline CV\% & 16,8 & 12,9 & 6,7 & 10,8 & 15,9 & 13,6 & 6,8 & 6,0 & 2,6 & 5,3 \\
\hline
\end{tabular}

${ }^{1 / \mathrm{A}}+\mathrm{M}$ : aveia- preta (Avena strigosa) no outono-inverno + mucuna-anã (Mucuna deeringiana) na primavera-verão; C + M: chicharo (Lathyrus sativus) no outono-inverno + mucuna-anã na primavera-verão; T + M: tremoço-branco (Lupinus albus) no outono-inverno e de mucuna-anã na primavera-verão.

Médias seguidas pelas mesmas letras minúsculas nas colunas, para cada local, e maiúsculas nas linhas não são diferentes entre si, pelo teste de Duncan, a 5\% de probabilidade. 


\section{CONCLUSÃO}

Pode-se substituir a cobertura seca usual de Brachiaria decumbens nas ruas da videira 'Niagara Rosada', na região de Campinas-SP, pela adubação verde intercalar com aveia-preta, chícharo ou tremoço-branco, no outono-inverno, seguidos de mucuna-anã, na primavera-verão, sem alteração prejudicial na produtividade quantitativa do parreiral.

\section{AGRADECIMENTOS}

Os autores agradecem à colaboração de Maria Andinalva C. Secco, José Valdomiro Secco, Ismael Luis Secco e Josué Carlos Secco, do Sítio dos Meninos, em Indaiatuba; aos meeiros João Razze, Paulo Colodiano e famílias; ao pesquisador científico José Luiz Hernandes, e funcionários de apoio do IAC, Paulo Eduardo Magalhães, Valdeir Biúdes Hermoso, Nereu Pedro dos Santos (in memoriam), Luzia Fátima da Silva, Tereza Sinotti, Amarildo C. da Silva, Nair A. dos Santos, Jorgina L. Vaz (in memoriam), Ivanilda dos Santos, Ocimara Aparecida Alves, Nelson A. da Silva, Aparecido Donizeti da S. Mendonça, Eujandir Cararetto, e aos estagiários Daniel B. de Sousa, Fabio Costa, Janaína D. de Oliveira, João Paulo Lopes, José Ernesto P. N. da Silva, Patrícia F. de S. Vieira e Regiane Rodrigues.

\section{REFERÊNCIAS}

ASSIS, K. C. de; NEIS, S.; SANTOS, S. C.; SILVA, S. M. da; SOUSA, R. D. de; LIMA, V. V. Produção e qualidade da videira cv. Niagara Rosada. In: CON GRESSO BRASILEIRO DE FRUTICULTURA, 20., ANNUAL MEETING OF THE INTERAMERICAN SOCIETY FOR TROPICAL HORTICULTURE, 54., 2008, Vitória. Resumos... Cabo Frio: Sociedade Brasileira de Fruticultura, 2008. CD-ROM

BENATO, E.A. Cuidados na colheita, manuseio e conservação de uvas de mesa. In: REGINA, M. de A. et al. (Ed.) Viticultura e enologia: atualizando conceitos. Caldas: EPAMIG-FECD, 2002. p.121-135.

BOTELHO, R. V. Efeitos do thidiazuron e do ácido giberélico sobre as características dos cachos dos cultivares de videira Vênus, Centennial Seedless e Niagara Rosada. 2002. 136f. Tese (Doutorado em Agronomia) - Faculdade de Ciências Agronômicas, Universidade Estadual Paulista, Botucatu, 2002.
BRAGA, F. G. Tratos culturais da videira Niagara Rosada. Suplemento Agrícola, São Paulo, n. 608, p.9, 1986.

BRASIL. Ministério da Agricultura. Secretaria Nacional de Defesa Agropecuária. Secretaria de Inspeção de Produtos Vegetais. Complementação de padrões de identidade e qualidade para suco, refresco e refrigerante de uva. Brasília, 2002. 29p.

BULISANI, E. A.; MIYASAKA, S. A. Adubação verde no estado de São Paulo. In: COSTA, M. B. da C. (Coord.). Adubação verde no sul do Brasil. Rio de Janeiro: AS-PTA, 1992. parte 2, p.59-81.

BULISANI, E. A.; ROSTON, A. J. Leguminosas: adubação verde e rotação de culturas. In: WUTKE, E. B.; BULISANI, E. A.; MASCARENHAS, H. A. $A$ (Coord.). Curso sobre adubação verde no Instituto Agronômico. Campinas: Instituto Agronômico, 1993. p.13-16 (Documentos, 35)

CALEGARI, A. Adubação verde no estado do Paraná. In: COSTA, M. B. da C. (Coord.). Adubação verde no sul do Brasil. Rio de Janeiro: AS-PTA, 1992. Parte II, p.83-119.

GHILARDI, A.A.; MAIA, M.L. Tecnologia, custo de produção e rentabilidade do cultivo de uva Niagara no Estado de São Paulo. Informações Econômicas, São Paulo, v.31, n.12, p.48-58, 2001.

KITAHARA, L.M. Serviço saiba mais: Jales: Casa da Agricultura de Jales, Embrapa Uva e Vinho. Disponível em: <http://www.brazilianfruit.org.br/ clippings/detalhe clippings.asp?tb clipping_codigo $=916>$. Acesso em: 10 out 2010 .

LEÃO, P. C. de S.; MAIA, J. D. G. Aspectos culturais em viticultura tropical: uvas de mesa. Informe Agropecuário, Belo Horizonte, v.19, n.194, p. 3439, 1998.

LEÃO, P.C. de S., SOUZA, E.E.G. da. Brotação e fertilidade de gemas em uvas sem sementes no Vale do São Francisco. Revista Brasileira de Fruticultura, Jaboticabal v.25, n.3, p.375-378, 2003.

MAIA, J. D. G.; CAMARGO, U. A. I - Implantação do vinhedo e manejo das plantas. In: MAIA, J.D.G.; KUHN, G.B. (Ed.). Cultivo da Niágara Rosada em áreas tropicais do Brasil. Bento Gonçalves: Embrapa Uva e Vinho, 2001. p.13- 23. 
MANERA, R. Plantas que mais dão do que tiram do chão. Revista Globo Rural, São Paulo, v.1, n.7, p.64-71, 1986.

MELO, G.W.B. de; MAIA, J.D.G. II - Manejo de plantas daninhas e adubação: 1 . Controle de plantas daninhas. In: MAIA, J.D.G.; KUHN, G.B. (Ed.). Cultivo da Niágara Rosada em áreas tropicais do Brasil. Bento Gonçalves: Embrapa Uva e Vinho, 2001. p.24-25.

MIQUELETTO, D. F.; CARDOSO, J.L.; MARTIN, N.B. Avaliação econômica da produção comercial de uva Niagara: uma aplicação do software CUSTAGRI 1.0. Informações Econômicas, São Paulo, v.30, n.11, p.7-15, 2000.

PIRES, E.J.P.; MARTINS, F.P. Técnicas de cultivo. In: POMMER, C.V. (Ed.). Uva: tecnologia de produção, pós-colheita, Mercado. Porto Alegre: Cinco Continentes, 2003. p.351-403.

POMMER, C. V.; PASSOS, I., R. da S.; TERRA, M. M.; PIRES, E. J. P. Variedades de videira para o Estado de São Paulo. Campinas: Instituto Agronômico, 1997. 59 p. (Boletim técnico, 166)

POMMER, C. V.; PIRES, E. J. P.; TERRA, M. M.; PASSOS, I., R. da S.; RIBEIRO, I.A. Uvas (Vitis spp.). In: FAHL, J. I. et al. (Ed.). Instruções agrícolas para as principais culturas econômicas. 6.ed. rev. atual. Campinas: Instituto Agronômico, 1998. p.158-162. (Boletim, 200)

SATO, G.S. Panorama da viticultura no Brasil. Informações Econômicas, São Paulo, v.30, n.11, p.7-15, nov. 2000 .

SIQUEIRA, C. SP: uva Niagara na terra da Itália. O Estado de São Paulo. 2008. Disponível em: $<$ http://www.paginarural.com.br/noticias detalhes. php?id=89499> . Acesso em: 10 out. 2008.

SOUSA, J. S. I. de; TERRA, M. M.; DECHEN, A. R. 7.3. Adubos verdes. In: SOUSA, J. S. I. de (Coord.). Uvas para o Brasil. Piracicaba: FEALQ, 1996. v.1, p. 417-420.

SOUSA, J. S. I. de; TERRA, M. M.; DECHEN, A. R. Adubação e nutrição da videira. In: SOUSA, J. S. I. de (Coord.). Uvas para o Brasil. Piracicaba: FEALQ, 1996. v.1, p.393-424.
TERRA, M.M.; PIRES, E.J.P.; POMMER, C.V.; BOTELHO, R.V. Produtividade da cultivar de uva de mesa Niagara Rosada sobre diferentes porta-enxertos em Monte Alegre do Sul-SP. Revista Brasileira de Fruticultura, Jaboticabal, v. 25, n. 3, p. 549-551, 2003.

TERRA, M. M.; PIRES, E. J. P.; POMMER, C. V.; PASSOS, I.R. da S.; MARTINS, F.P; RIBEIRO, I.J.A. Comportamento de porta-enxertos para o cultivar de uva de mesa Niagara Rosada, em Jundiai, SP. In: CONGRESSO BRASILEIRO DE FRUTICULTURA, 9., 1987, Campinas. Anais... Campinas: Sociedade Brasileira de Fruticultura, 1987. p.721-725.

TERRA, M. M.; PIRES, E. J. P.; POMMER, C. V.; NOGUEIRA, N. A. M. Tecnologia para produção de uva Itália na região noroeste do Estado de São Paulo. 2.ed. rev. atual. Campinas: CATI, 1998. 81p. (Documento Técnico, 97)

VERDI, A.R. A vitivinicultura em diferentes contextos. In: BUENO, S. C. S., et al. (Coord.). Vinhedo Paulista. Campinas: CATI, 2010. p.33-52.

VIILA MAIOR, V. de. Manual de viticultura prática. 2.ed. Porto: Chardron, 1981. 619p.

WUTKE, E. B. Adubação verde: manejo da fitomassa e espécies utilizadas no Estado de São Paulo. In: WUTKE, E. B.; BULISANI, E. A.; MASCARENHAS, H. A. A. (Coord.). Curso sobre adubação verde no Instituto Agronômico, 1. Campinas: Instituto Agronômico, 1993. p.17-29. (Documentos, 35)

WUTKE, E. B. Adubação verde na agricultura familiar. In: CATI (Org.). Sistema de produção: sustentabilidade para a Agricultura Familiar. Campinas, 2001, p. 77-104.

WUTKE, E.; TRANI, P.E.; AMBROSANO, E.J.; DRUGOWICH, M.I. Adubação verde no Estado de São Paulo. Campinas: CATI, 2009. 89p. (Boletim técnico, 249)

WUTKE, E.B.; TERRA, M.M.; PIRES, E.J. P. Cobertura vegetal do solo na cultura da videira. In: BUENO, S.C.S. et al. (Coord.). Vinhedo paulista. Campinas: CATI, 2010. p.87-105. 
WUTKE, E.B.; CARVALHO, C.R.L.; COSTA, F.; TERRA, M.M.; PIRES, E.J.P.; SECCO, I.L. Qualidade de frutos de videira 'Niagara Rosada' em cultivo intercalar com gramínea e leguminosas. Revista Brasileira de Fruticultura, Jaboticabal, v. 26, n. 1, p. 92-96, 2004.
WUTKE, E. B.; TERRA, M. M.; PIRES, E. J. P.; COSTA, F.; SECCO, I. L.; RIBEIRO, I. J. A. Influência da cobertura vegetal do solo na qualidade dos frutos de videira 'Niagara Rosada'. Revista Brasileira de Fruticultura, Jaboticabal, v. 27, n. 3, p. 434-439, 2005. 